\title{
PRODUCER PERCEPTIONS AND WILLINGNESS TO PAY FOR AGRICULTURAL EXTENSION SERVICES IN ADA EAST DISTRICT OF GHANA
}

\author{
Frank Boe Otishua, Benjamin Tetteh Anang*, Stephen Mintah \\ Department of Agricultural Economics and Extension, Faculty of Agriculture, \\ University for Development Studies, Tamale, Ghana \\ *E-mail: benjamin.anang@uds.edu.gh \\ ORCID: 0000-0003-0093-2660
}

\begin{abstract}
Agricultural extension delivery in most developing countries is confronted with numerous challenges that hamper effective service delivery. The challenges, mainly budgetary in nature, have led to calls for cost-sharing in the delivery of agricultural extension services to farmers. However, there is not sufficient empirical evidence that supports the preparedness of producers to pay for extension services in most developing countries. Also, farmers' readiness to pay for agricultural extension services will depend on their perceptions of the effectiveness of the extension system. Relying on survey data, this study combined contingent valuation method (CVM) with Tobit modeling to estimate smallholders' willingness to pay (WTP) for agricultural extension services (AESs) in Ada East District of Ghana. Majority of the respondents $(90.6 \%)$ indicated willingness to pay for AESs. Producers expressed willingness to pay $\mathrm{GH} \phi 190$ for agricultural extension services for the cropping season. WTP was influenced by farmer's age, farm size, farm income, and marital status. Producers were generally dissatisfied with agricultural extension service delivery. Hence, efforts to promote privatization of extension service must take into account measures to enhance the quality of service delivery and frequency of visits.
\end{abstract}

\section{KEY WORDS}

Agricultural extension, contingent valuation method, perceptions, Tobit model, willingness to pay, Ghana.

Agriculture is the mainstay of many sub-Saharan African countries and contributes immensely to employment creation, poverty reduction, food and income security. Sustainable rural development in Africa depends largely on the performance of the agricultural sector which is a major contributor to poverty alleviation strategies in poor countries. Notwithstanding the notable contribution of agriculture, transformation in the sector has been rather slow, resulting in slowdown in agricultural growth resulting in poor economic performance of many African countries including Ghana. Agricultural transformation in Africa is dependent on disseminating the required information at the right time to producers who are key actors in the agricultural sector. This assertion is supported by Asiedu-Darko (2013) in his study on agricultural extension delivery in Ghana. Thus, the need for an effective agricultural extension system in Ghana and other developing countries cannot be overemphasized. Agricultural extension is crucial in raising farmers' level of technical knowhow resulting in higher level of productivity. Agricultural extension is particularly important for rural development in less developed nations because agricultural production is pivotal to rural livelihood (Temesgen and Tola, 2015). Regarding the impact of extension on peasant agriculture, Anang et al. (2020) identified extension service as a contributor to farm income and technology adoption in northern Ghana.

In Ghana, agricultural extension is largely a public service carried out by agricultural extension agents (AEAs) in the department of agriculture in the district assemblies (local government unit). Historically, agricultural extension in many developing countries has been perceived as a public good. Farmers were regarded as poor who needed state support in the form of services such as extension advice and farm subsidies. However, in recent times, there is increasing demand on agricultural extension to effectively meet the needs of 
producers with regards to production and linkage with markets (Rivera and Sulaiman, 2009). Ali et al. (2008) observed that globally, there are attempts to privatize agricultural extension delivery by public institutions due to ineffectiveness. Notwithstanding this realization, efforts at privatizing agricultural extension services (AESs) has not achieved the desired result in many developing countries such as Ghana. The need for commercialization of AESs has become more imperative nowadays in the face of shortage of extension personnel and lack of access by smallholders to extension services especially in rural areas.

Private extension service is regarded to be demand-driven and cost-effective, hence expected to lead to service quality and efficiency. Farmers desire improved entrepreneurial knowledge, improved access to input and output markets. This makes the market for private extension service a likely option in the face of current challenges facing public extension services in many developing countries. However, just like any private good, consumers' WTP is important for the development of an efficient private extension market. According to Parkinson (2009), successful privatization of agricultural extension hinges on farmers' demand for the services of private extension service providers as well as producers' capacity to afford such services. This assertion is reiterated by Kidd et al. (2000) who noted that the only way to successfully commercialize AESs is when there is willingness on the part of producers to patronize these services at a fee. Van Crowder (2000) further differentiated between producers' WTP and their ability to pay, stressing that the determination of fee structures must factor in the latter. Ajayi (2017) demonstrated that farmers' ability to pay for AES in Nigeria was positively related to their WTP. Farmers' lack of surplus financial resources is therefore a critical factor in privatization of AESs among the rural poor.

In moving from a public good to a private good, there is the need to make AESs relevant and attractive to farmers. This is because agricultural extension is a major strategy for rural development, which is expected to help producers to identify their challenges, find remedies to them, and take necessary action (Anaeto et al. 2012). The ultimate aim of AES is to improve productivity and incomes of farmers (Kassem, 2014). Farmers' perceptions about the effectiveness and impact of AESs are therefore important in achieving a robust extension system since they are major stakeholders and end-users of any extension programme.

Usually, farmers are blamed for not adopting innovations introduced by agricultural extension workers, without much consideration of the effectiveness of the extension delivery system itself. Logistical constraints, low motivation of extension staff, high extension worker to farmer ratio, among others, have been cited as challenges to AES delivery in most less developed countries. All these challenges have implications for extension service delivery, farmer satisfaction with the extension system, and the resultant effect on farmers' productivity and farm income.

Abraham et al. (2012) observed that the principal source of agricultural information for fish farmers in Kwara State, Nigeria was fellow farmers while extension agents were fifth in the ranking. This result highlights challenges with the extension system as pertains in many developing countries. Improper design of extension programs and messages have been identified as some of the challenges confronting effective extension delivery in Ghana and many developing countries (Anang et al., 2020). The relevance and benefits of extension programs and services to farmers have been found to stimulate an interest to pay for these services (Ajayi, 2006; Farinde and Atteh, 2009). AES must therefore be designed with farmers' preferred needs in mind to make them attractive and acceptable.

The questions which come to the fore, which are the motivation for this study, include the following: (1) what are producers' perceptions about the effectiveness and impact of AES on their farming activities? (2) are Ghanaian smallholders willing to pay for AESs, and if so, what amount? Answers to these questions are relevant to improve extension service delivery as well as inform policy makers on the modalities to transition from a public extension system to a privatized, commercial system. The overall goal is to improve extension service delivery, accessibility, productive capacity and farm income of farm households.

The study's core objective is to evaluate producers' perceptions and readiness to pay for AES in Ada East District of south-eastern Ghana. The study intents to achieve the 
following specific objectives: (1) to evaluate framers' perceptions of the effectiveness of AESs; and (2) to evaluate producers' willingness to pay for AES.

\section{LITERATURE REVIEW}

WTP for Agricultural Extension Services. Smallholders in developing countries depend to a large extent on public agricultural extension services as their source of agricultural information. The importance of public agricultural extension services to smallholders can therefore not be overemphasized. However, challenges in accessing AES by smallholder farmers is an increasing phenomenon, with the call for private extension services (fee-based services) gaining momentum in recent years (see Uddin et al., 2016). Farmers perceive agricultural extension as a public good and have not developed a penchant for private extension which comes at a cost. Efforts at introducing private extension services will make extension a private good and hence more demand-driven as against the current supplydriven nature of agricultural extension in most developing countries including Ghana. It is in this light that policy makers in developing countries are exploring ways to make private extension service delivery operational to enhance access to extension services. To realize this goal, there is the need to fully understand producers' WTP for extension and their perception of AES delivery in general.

A number of studies on willingness to pay for AESs in less developed countries can be found in the existing literature (see Ajayi, 2006; Foti et al., 2007; Ozor et al., 2013; Spencer et al., 2018; Uddin et al., 2016). Studies have shown that WTP for AESs is positively related to farm income as well as relevance of the program and services to farmers in Nigeria (Ajayi, 2006; Farinde and Atteh, 2009). According to Uddin et al. (2016), farmers' WTP for agricultural extension in Bangladesh is conditioned on the quality of service. Farmers' income from agriculture, farming experience, and years of schooling were found to have significant influence on WTP for extensions services. The authors further revealed that $81 \%$ of farmers indicated willingness to pay. A study in Zimbabwe by Foti et al. (2007) also showed that higher income from agriculture enhanced WTP. Authors such as Foti et al. (2007) and Oladele (2008) identified farm size as a variable influencing WTP for agricultural extension in Zimbabwe and Nigeria, respectively. Ajayi (2017) noted that WTP for agricultural extensions services is related to age, annual income, gender of the farmer, farm size, participation in organization, ability to pay, attitude towards extension agents as well as farmers' assessment of the extension activities.

Spence et al. (2018) identified the complexity in moving to a user-pay extension system in Malawi and identified the key role that private service providers play in meeting the needs of farmers. Farmers' WTP for extensions services has also been shown to be related to what they perceive to be their needs with regards to farming (Budak et al., 2010; Oladele, 2008).

There is paucity of research on willingness to pay for AESs in Ghana and this study seeks to fill that void. The few studies available include Ackah-Nyamike (2003) who observed that $82 \%$ of their respondents indicated willingness to pay for AESs. The preferred mode of payment revealed that $53 \%$ of producers are willing to pay with their crop harvest while $47 \%$ preferred payment in cash.

Contingent Valuation Method (CVM). Continent valuation is the preferred approach for estimating willingness to pay. The CVM has been demonstrated to be the most common of the available methods for monetary valuation of services, such as extension delivery, due to its applicability in varied situations (Borzykowski et al., 2017). In a hypothesized scenario, individuals are requested to give the amount they would willingly pay for a service or whether they would agree to make payment or suggest bid amount for the service. The method is useful when there is no real market or actual consumer expenditure to use for the valuation (Boyle, 2017).

There are diverse elicitation formats in acquiring respondents' WTP using CVM. These include the open-ended question, the game of bidding, and the dichotomous choice approach. The open-ended format is the simplest format in CVM. With the open-ended question format, respondents are requested to give the amount they would willingly pay for a 
service. In this case, no specific bid amount is presented to the respondent. In the bidding game format, an individual is asked if he or she is willing to pay a specific amount of money for the service. If the response is "yes", he or she will be asked the same question for an increased bid amount, and increased bid amounts are asked constantly until the respondent says "no". Likewise, if "no" is the response to the initial bid amount, decreased bid amounts are constantly asked until the respondent says "yes". The problem with this format is that the estimated WTP tends to have correlation with the initial value, which is called starting point bias (Mitchell and Carson, 1989).

There are two procedures under the dichotomous choice approach. The first procedure is the single-bounded dichotomous choice (SBDC) approach, where an individual is presented with a proposed amount for the service and asked to indicate willingness to pay. Here, the individual either agrees to pay the proposed amount or not. The approach is assumed to have less bias because respondents have no motivation to strategically bias their answers toward the desired outcome (Borzykowski et al., 2017).

The second procedure is the double-bounded dichotomous choice (DBDC) approach, which has some similarity to the SBDC approach. The initial amount presented to the bidder is called the initial bid price. A higher bid is presented to individuals who express willingness to pay the initial bid price. The bid price is adjusted upwards by a fixed proportion until the individual expresses unwillingness to pay. Similarly, a lower bid price is presented to individuals who express unwillingness to pay the initial bid price. The DBDC approach provides elaborate information and decreases the need for a large sample size compared to that which is needed when using the single-bounded dichotomous choice (Borzykowski et al., 2017).

\section{METHODS OF RESEARCH}

Ada East District is situated in south-eastern Ghana, specifically in the Greater Accra Region. It has Ada Foah as the district capital. Ada East district is part of the coastal savannah zone with an average annual rainfall of $800 \mathrm{~m}$. The district is noted for the cultivation of pepper, tomato, water melon, cassava, onion, carrot and okra. Some farmers also engage in rearing of cattle, sheep, goats and pigs whiles others engage in fishing and fish processing.

Identification and selection of farmers for the study was done using multi-stage sampling. First, eight (8) communities were randomly selected to take into account geographical spread of farmers. This was followed by a random selection of 20 farmers from each community to provide a total of 160 respondents. Questionnaires were administered to farmers using face-to-face interviews. The enumerators aided the process by translating the questions into the local dialect for persons with low literacy.

CVM can be either open-ended or close-ended. With the open-ended format, individuals are simply requested to indicate how much they would willingly pay for extension services. The close-ended format however can take a single-bounded (SBDC) or doublebounded (DBDC) format. With the SBDC format, respondents indicate their willingness to pay $\mathrm{GH} \phi \mathrm{X}$ for AESs. The response is dichotomous requiring a "yes" or "no" answer. With the DBDC format, individuals are presented with the choice whether they would agree to pay for AESs. For a "no" answer, there is no further question; but if the response is "yes", the individual is requested to indicate willingness to pay $\mathrm{GH} \phi X$ price premium for extension services (the initial bid). The dichotomous response (yes or no) from the initial question is followed by another question with a dichotomous choice. A respondent who responds "yes" to the initial question will be asked again if she/he is willing to pay $\mathrm{GH} \phi \mathrm{Y}$ price premium which is higher than the initial price premium, $\mathrm{GH} \phi \mathrm{X}$. The potential response for the second question is also dichotomous (yes or no). Conversely, a respondent who responds "no" to the initial question will be asked whether he/she is willing to pay $\mathrm{GH} \phi \mathrm{Z}$ price premium which is below the initial premium, GH $\phi X$. The potential answer for this question is either "yes" or "no". Depending on whether the response is "yes" or "no", a higher or lower bid is presented to the respondent (based on a proportionate increase or decrease in the initial bid amount), 
until the respondent has no inclination to pay a higher or lower bid than the amount that she/he has indicated a willingness to pay. Based on the responses, five potential outcomes can be derived from the DCDB format. Assuming we represented the initial bid with $\beta_{I}$, lower bid with $\beta_{L}$ and upper bid with $\beta_{U}$, then the potential outcomes will be given as follows:

Zero WTP: Respondents unwilling to pay for AESs. Respondents are referred to as zero WTP bidders.

No-No WTP: Respondents who express willingness to pay additional cost for extension services but lower than the initial and lower bid. Respondents are referred to as lowest WTP bidders.

No-Yes WTP: Respondents who express willingness to pay additional cost for AESs between the initial bid and the lower bid. Respondents are referred to as lower WTP bidders.

Yes-No WTP: Respondents who express willingness to pay additional cost for AESs between the initial bid and the upper bid. Respondents are referred to as moderate WTP bidders.

Yes-Yes WTP: Respondents who express willingness to pay additional cost for AESs beyond the initial bid and the upper bid. Respondents are referred to as higher WTP bidders.

Farmers' perceptions of the effectiveness of AESs were analyzed using descriptive statistics (percentages, frequencies and tables). A 5-point Likert scale was constructed to measure how producers perceived the effectiveness of AESs. Summary statistics such as means and standard deviations for the various perception statements were obtained and reported.

The main approaches in the literature for estimating the factors determining producers' WTP for extension services are the binary probit (or logit) and censured Tobit models. For example, the probit model was used to assess factors influencing WTP by authors such as Budak et al. (2010) and Mwaura et al. (2010) while the Tobit model has been used by Shausi et a. (2019) and Uddin et al. (2016). There are other authors such as Uddin et al. (2016) and Temesgen and Tola (2015) who used the logit model instead of the probit model to assess WTP. The estimation approach to use is dependent on whether the response variable is dichotomous or censored. For dichotomous dependent variables, the probit or logit model is suitable, while for censored data, the Tobit model is appropriate.

The dependent variable in this study is censored hence a Tobit model was adopted to identify the factors determining actual amounts producers expressed willingness to pay, which was elicited using the DBDC format. The Tobit model is appropriate for this analysis because some of the WTP values are censored at zero (0) for those unwilling to pay.

The Tobit model can be expressed as a latent variable model. Suppose we represent the amount that farmers are willing to pay by $y_{i}$. A latent (unobserved) continuous dependent variable $y_{i}^{*}$ is linearly related to a set of independent variables, $x_{i}$ as follows:

$$
y_{i}^{*}=\beta x_{i}+v_{i}, v_{i} \sim N\left(0, \sigma^{2}\right)
$$

Where: $\beta$ represents a vector of unknown coefficients and $v_{i}$ represents the random error. The relationship between the observed variable $y_{i}$, and the latent variable is defined as follows.

$$
y_{i}= \begin{cases}y_{i}^{*} & \text { if } y_{i}^{*}>0 \\ 0 & \text { if } y_{i}^{*} \leq 0\end{cases}
$$

The empirical Tobit model for the amount that producers are willing to pay is presented as follows:

$$
y_{i}^{*}=\beta_{0}+\sum_{k=1}^{9} \beta_{k} x_{i k}+v_{i}
$$

where $x_{i}$ denotes the variables influencing the amount respondents are willing to pay, $\beta_{k}$ represents unknown coefficients, while $v_{i}$ denotes random errors. 
The independent variables for the WTP model included sex, age, marital and educational status, farming experience, farm size, annual farm income, participation in offfarm work and number of extension visits. The variables were chosen based on a priori expectation and the extant literature (see Ajayi, 2017; Uddin et al., 2016; Mabe et al., 2014; Ozor et al., 2013; Oladele, 2008). Education, farming experience, farm size, income from farming and number of extension visits are expected to enhance WTP, while the direction of influence of age and sex are indeterminate. Education, farming experience and access to extension improve human capital and exposure to improved methods of production, hence WTP for extension. An increase in farm income is expected to enhance ability to pay while respondents with larger farms are expected to have greater demand for agricultural information to enhance production, hence higher WTP. Also, WTP for extension is expected to increase with participation in off-farm work through the income effect.

\section{RESULTS AND DISCUSSION}

Characteristics of the Sampled Farmers. Majority of the respondents were female farmers (Table 1), indicating high female participation in tomato farming in the study area. The farmers had average age of 43 years with $75 \%$ having obtained formal education. Respondents had mean household size of 7 members and farmed an average of 3 acres of tomato. Average annual income of the respondents was $\mathrm{GH} \phi 11,089$ with average farming experience of 16 years. Also, $45 \%$ of the respondents engaged in off-farm work while $67 \%$ owned the land on which they farmed. Farmers had on average one extension visit, indicating that farmers are poorly served by the extension system. This result is corroborated by Anang et al. (2020) in a survey of small-scale producers in northern Ghana. The low access to extension services in Ghana is further buttressed by Abdallah and Abdul-Rahaman (2016). The respondents indicated willingness to pay $\mathrm{GH} \phi 190$ for extension, with highest stated amount of $\mathrm{GH} \phi 500$.

Table 1 - Description of Variables

\begin{tabular}{llll}
\hline Variable & Measurement & Mean & S. D. \\
\hline Amount farmers are willing to pay & Ghana cedi & 0 & 500 \\
Sex of farmer & 1 for male; 0 otherwise & 0.338 & 0.474 \\
Age of respondent & Years & 43.42 & 12.29 \\
Educational status & Dummy: 1 for educated; 0 otherwise & 0.750 & 0.434 \\
Marital status & Dummy: 1 for married; 0 otherwise & 0.825 & 0.381 \\
Tomato farm size & Acres & 3.434 & 2.644 \\
Farm income & Ghana cedi & 11089 & 17403 \\
Off-farm work & Dummy: 1 for yes; 0 otherwise & 0.450 & 0.499 \\
Farming experience & Years & 16.34 & 11.65 \\
Number of extension visits & Number & 0.675 & 1.267 \\
\hline
\end{tabular}

S.D. indicates standard deviation. 1 Ghana cedi $=$ US\$ 0.19 .

Elicitation of WTP. Elicitation of WTP was carried out using the DBDC contingent valuation method. As shown in Table 2, 9.4\% of the respondents expressed Zero WTP. In other words, they represent farmers unwilling to pay for AESs. Respondents who expressed No-No WTP constituted $11.9 \%$ of the sample. This represents those unwilling to pay the initial bid price of $\mathrm{GH} \phi 200$, as well as the lower bid price of $\mathrm{GH} \phi 100$, except an amount lower that the lower bid prize. Furthermore, $20 \%$ of farmers expressed No-Yes WTP, representing those who expressed willingness to pay an amount between the initial bid price of $\mathrm{GH} \phi 200$ and the lower bid price of $\mathrm{GH} \phi 100$. Also, 33.7\% indicated Yes-No WTP, indicating those willing to pay an amount between the initial bid price of $\mathrm{GH} \phi 200$ and upper bid price (GHф300). Finally, 25\% indicated Yes-Yes WTP, representing those who expressed willingness to pay the upper bid price of $\mathrm{GH} \phi 300$ or more. 
Table 2 - Elicitation of WTP Using the DBDC Contingent Valuation Method

\begin{tabular}{lll}
\hline Variable & Frequency & Percentage \\
\hline Zero WTP & 15 & 9.4 \\
No-No WTP & 19 & 11.9 \\
No-Yes WTP & 32 & 20 \\
Yes-No WTP & 54 & 33.7 \\
Yes-Yes WTP & 40 & 25 \\
Total & 160 & 100 \\
\hline
\end{tabular}

Distribution of Final Bid Price for Extension Services. Table 3 provides the responses regarding the amount producers are willing to pay for AESs.

Table 3 - Distribution of Final Bid Price for Agricultural Extension Services

\begin{tabular}{llll}
\hline Final bid price $(\mathrm{GH} \phi)$ & Frequency & Percent & Cumulative \\
\hline 0 & 15 & 9.38 & 9.38 \\
50 & 19 & 11.88 & 21.25 \\
100 & 25 & 15.63 & 36.88 \\
150 & 7 & 4.38 & 41.25 \\
200 & 36 & 22.5 & 63.75 \\
250 & 18 & 11.25 & 75 \\
300 & 23 & 14.38 & 89.38 \\
350 & 2 & 1.25 & 90.63 \\
400 & 7 & 4.38 & 95 \\
450 & 3 & 1.88 & 96.88 \\
500 & 5 & 3.13 & 100 \\
\hline
\end{tabular}

Mean $=190.3 ;$ standard deviation $=125.8$.

From the results, farmers expressed willingness to pay $\mathrm{GH} \phi 190.3$ for extension service per cropping season. Those who expressed unwillingness to pay formed $9.4 \%$ of those interviewed. Also, $22.5 \%$ expressed willingness to pay $\mathrm{GH} \phi 200$, while $15.6 \%$ and $14.4 \%$ would willingly pay $\mathrm{GH} \phi 100$ and $\mathrm{GH} \phi 300$, respectively. Furthermore, $11.9 \%$ of farmers indicated willingness to pay $\mathrm{GH} \phi 50$ while $11.3 \%$ would willingly pay $\mathrm{GH} \phi 250$. The highest bid price a farmer was willing to pay was $\mathrm{GH} \phi 500$ and this corresponded to $3 \%$ of the farmers. The findings indicate willingness of producers to pay for AESs, which suggests that privatization of extension services could yield positive outcome in Ghana.

Determinants of WTP for Agricultural Extension. WTP for extension services was estimated using a censured Tobit model following similar approaches in the literature. For example, the Tobit model was used to assess factors influencing WTP by authors such as Shausi et a. (2019) and Uddin et al. (2016). The dependent variable for the Tobit model is censored, that is, some of the WTP values are censored at zero (0) for those unwilling to pay for AESs, while the rest are continuous. The double-bounded dichotomous choice CVM was applied to ascertain the actual amounts that producers were willing to pay. The Tobit regression estimates of farmers' WTP are presented in Table 4.

Table 4 - Factors Affecting WTP for AESs

\begin{tabular}{llll}
\hline Variable & Coefficient & Std. Error & P-value \\
\hline Sex of farmer & -12.27 & 20.34 & 0.547 \\
Age of farmer & $-2.336^{\star *}$ & 1.133 & 0.041 \\
Educational status & -34.96 & 23.74 & 0.143 \\
Marital status & $46.54^{*}$ & 24.53 & 0.060 \\
Farming experience & -0.355 & 1.112 & 0.750 \\
Farm size & $9.623^{\star * *}$ & 3.449 & 0.006 \\
Farm income & $0.003^{\star * *}$ & 0.001 & 0.000 \\
Off-farm work & 24.46 & 19.00 & 0.200 \\
Number of extension visits & 3.648 & 7.513 & 0.628 \\
Constant & $202.2^{\star * *}$ & 56.69 & 0.000 \\
\hline Log likelihood & -907.0 & & \\
LR chi2(9) & 59.00 & & \\
Prob > chi squared & 0.000 & & \\
Pseudo R-squared & 0.032 & & \\
\hline
\end{tabular}

${ }^{* * *},{ }^{* *}$ and * signify significant at $1 \%, 5 \%$ and $10 \%$ level, respectively. 
The results indicate that WTP for extension increased with farm size in line with a priori expectation. Producers with larger landholdings may be progressive farmers who rely on extension services to maximize productivity and farm profits. The findings agree with Temesgen and Tola (2015) who observed that WTP increased with farm income in Eastern Ethiopia. Another study by Mabe et al. (2014) in Savelugu-Nanton Municipal of northern Ghana also indicted that WTP for weather forecast information increased with farm size.

Similarly, WTP for extension increased with farm income which agrees with a priori expectation. Producers with higher farm income are anticipated to be more probable to pay more for AESs as opposed to those with lower income. The result agrees with Temesgen and Tola (2015) in their study in Eastern Ethiopia and Ajayi (2017) in a study in Nigeria. Mabe et al. (2014) similarly demonstrated in their study in Savelugu-Nantom Municipal of northern Ghana that WTP for weather forecast information increased with on-farm income.

Producer's age was inversely related to willingness to pay. What the result seems to imply is that as farmers get older, they tend to rely more on their personal knowledge and experiences and thus less probable to pay for the services of agricultural extension. The result is supported by Temesgen and Tola (2015) in a study in Ethiopia but at variance with Ajayi (2017) in a study in Nigeria.

Marital status captures the role of intra-household decision-making and was positively related to WTP at $10 \%$ level. The result indicates that respondents who are married are willing to pay higher amounts for AESs vis-à-vis the unmarried. Married couples may be able to pool together financial resources to pay for the cost of production such as payment for extension services.

Assessment of Effectiveness of AESs. Producer perceptions about the effectiveness of AES delivery is essential to WTP decisions. Producers' assessment of the effectiveness of the extension system is presented in Table 5. Several perception statements were included in the analysis taking into account farmers' expectations of the extension system.

Table 5 - Assessment of Effectiveness of Agricultural Extension Services

\begin{tabular}{|c|c|c|c|c|c|c|c|}
\hline Perception statement & HS & $\mathrm{S}$ & I & $\mathrm{D}$ & HD & Mean & S.D. \\
\hline Farmers' opinion towards frequency of individual farm visits by AEAs & 3 & 4 & 10 & 12 & 131 & 4.65 & 0.86 \\
\hline Farmers' opinion towards effectiveness of field visits by extension agents & 2 & 4 & 11 & 18 & 125 & 4.63 & 0.82 \\
\hline Effectiveness of office call as an extension delivery method to farmers & 3 & 0 & 6 & 41 & 110 & 4.59 & 0.94 \\
\hline $\begin{array}{l}\text { Farmers' opinion towards distributions of inputs (improved seeds) by extension } \\
\text { agents }\end{array}$ & 1 & 4 & 2 & 48 & 105 & 4.58 & 0.71 \\
\hline Farmers' opinion towards demonstration of new technologies by AEAs & 4 & 6 & 14 & 28 & 108 & 4.44 & 0.98 \\
\hline Farmers' opinion about training given by extension agents & 3 & 6 & 15 & 39 & 97 & 4.38 & 0.94 \\
\hline $\begin{array}{l}\text { Farmers' opinion towards usefulness of information delivered by extension } \\
\text { agents }\end{array}$ & 5 & 12 & 26 & 21 & 96 & 4.19 & 1.15 \\
\hline $\begin{array}{l}\text { Extent to which farmer is equipped by extension service to advice other } \\
\text { farmers }\end{array}$ & 11 & 27 & 19 & 16 & 87 & 3.86 & 1.4 \\
\hline Effectiveness of telephone call as an extension delivery method to farmers & 8 & 11 & 40 & 52 & 49 & 3.77 & 1.11 \\
\hline $\begin{array}{l}\text { Farmers' satisfaction with extension agents in the distribution of fertilizer } \\
\text { coupons }\end{array}$ & 26 & 31 & 28 & 20 & 55 & 3.29 & 1.51 \\
\hline
\end{tabular}

Note: $H S=1$ (Highly satisfied); $S=2$ (Satisfied); I = 3 (Indifferent); $D=4$ (Dissatisfied); HD = 5 (Highly Dissatisfied).

The results indicate that farmers are highly dissatisfied with the frequency of individual farm visits by extension agents, effectiveness of office call as an extension delivery method, distribution of production inputs by extension agents, and effectiveness of field visits by extension staff. The results further indicate that farmers are dissatisfied with training given by extension staff, demonstration of new technologies by extension agents, effectiveness of telephone call as an extension delivery method, usefulness of the extension message, and the extent to which farmers are equipped by extension service to offer advice to other farmers. From the results, farmers were indifferent in their assessment regarding the distribution of fertilizer coupons by extension agents. Overall, farmers were dissatisfied with AES delivery, which is expected to influence their WTP. Elias et al. (2016) showed that $39 \%$ of their respondents were dissatisfied with agricultural extension service delivery in North 
West Ethiopia. According to the authors, farmers' satisfaction with extension is linked to frequency of contact and the perception of benefits from extension.

\section{CONCLUSION}

The study assessed farmers' perceptions of AES delivery and WTP for extension. The results indicate that farmers are generally dissatisfied with agricultural extension service delivery. Farmers have a poor perception of the effectiveness of AESs on their production activities. The poor perception of producers about the effectiveness of AESs may be attributed to inadequate extension staff, inadequate extension visits as well as extension methods and messages that are not well-tailored to the needs of producers. Respondents were willing to pay GH $\phi 190.3$ for AESs. Producers' age, marital status, size of farmland and income from tomato production were the main determinants of WTP for extension services.

AES delivery is critical to agricultural development in developing economies where most farmers rely on public extension service, which has come under criticisms for being ineffective due to several challenges. Introducing cost-sharing in extension delivery is anticipated to enhance performance and effectiveness but this depends on willingness of producers to pay for the service. Successful introduction of cost-sharing in AES delivery is dependent on how farmers perceive the effectiveness of extension service. Thus, to achieve cost-sharing, there is the need to address the constraints limiting effective service delivery. Attention must be given to the frequency of visits, tailoring extension messages to producers' needs, as well as the provision of training and demonstrations on modern production practices. The establishment of a market for extension services should consider targeting younger farmers, who were willing to pay more for AESs. Similarly, producers with relatively larger farms and higher farm income should be targeted for cost-sharing in extension service delivery as they expressed willingness to pay more for extension.

\section{REFERENCES}

1. Abdallah, A.H., and Abdul-Rahaman, A., 2016. Determinants of access to agricultural extension services: Evidence from smallholder rural women in Northern Ghana. Asian Journal of Agricultural Extension, Economics and Sociology, 9 (3), 1-8.

2. Abraham, F., Kayode, B.I., Omonlumhen, U.P., 2012. Willingness-to-pay for agricultural extension services by fish farmers in Nigeria: a case study of Kwara State, Niger. Journal of Sustainable Development in Africa, 14 (5), 197-207.

3. Ackah-Nyamike, E.E., 2003. Expanding the funding base for public agricultural extension delivery in Ghana: an analysis of farmer willingness to pay for extension services. PhD Thesis submitted to the Department of International and Rural Development, University of Reading.

4. Ajayi, A. O., 2006. An assessment of farmers' willingness to pay for extension services using the contingent valuation method (CVM): The case of Oyo State, Nigeria. The Journal of Agricultural Education and Extension, 12 (2), 97-108.

5. Ajayi, O., 2017. Farmers' willingness to participate in the financing of agricultural extension services in Oyo State, Nigeria: A factor analysis. Journal of Sustainable Development, 1 (2), 2-11.

6. Ali, S., Ahmad, M., Ali, T., Din, I., Iqbal, M.Z., 2008. Farmers' willingness to pay (WTP) for advisory services by private sector extension: The case of Punjab. Pakistan Journal of Agricultural Sciences, 45 (3), 107-111.

7. Anaeto, F.C., Asiabaka, C.C., Nnadi, F.N., Ajaero, J.O., Aja, O.O., Ugwoke, F.O., Ukpongson, M.U. and Onweagba, A.E., 2012. The role of extension officers and extension services in the development of agriculture in Nigeria. Journal of Agricultural Research, 1 (6), 180-185.

8. Anang, B.T., Bäckman, S., Sipiläinen, T., 2020. Adoption and income effects of agricultural extension in northern Ghana. Scientific African 7 (2020) e00219. 
9. Asiedu-Darko, E., 2013. Agricultural extension delivery in Ghana: A case study of factors affecting it in Ashanti, Eastern and Northern regions of Ghana. Journal of Agricultural Extension, and Rural Development, 5 (2), $37-41$.

10. Borzykowski, N., Baranzini, A., 2017. Scope Effects in Contingent Valuation: Does the Assumed Statistical Distribution of WTP Matter? Ecological Economics, 144, 319-329.

11. Boyle, K. J., 2017. Contingent Valuation in Practice. A Primer on Nonmarket Valuation, pp. 83-131.

12. Budak, D.B., Budak, F., Kacira, O. O., 2010. Livestock producers' needs and willingness to pay for extension services in Adana province of Turkey. African Journal of Agricultural Research, 5(11): 1187-1190.

13. Elias, A., Nohmi, M., Yasunobu, K., 2016. Farmers' Satisfaction with Agricultural Extension Service and Its Influencing Factors: A Case Study in North West Ethiopia. Journal of Agricultural Science and Technology, 18(1), 39-53.

14. Farinde, A.J., Atteh, A.P., 2009. Tending toward Extension Privatization in Nigeria: An Assessment of Arable Crop Farmers' Willingness to Pay for Extension Services in Niger State of Nigeria. Journal of Agricultural and Food Information, 10 (1), 63-75.

15. Foti, R., Nyakudya, I., Moyo, M., Chikuvire, J. 2007. Determinants of Farmer Demand for "Fee-for-Service" Extension in Zimbabwe: The Case of Mashonaland Central Province. Journal of International Agricultural and Extension Education, 14 (1), 95-104.

16. Kassem, H.S., 2014. Effectiveness of different agricultural extension methods in providing knowledge and skills in disease prevention: A case of Smallholder Poultry Production Systems in Dakhalia Governorate of Egypt. Asian Journal of Agricultural Extension, Economics and Sociology, 3 (2): 91-107.

17. Kidd, A.D., Lamers, J.P.A., Ficarelli, P.P., Hoffmann, V., 2000. Privatizing agricultural extension: caveat emptor. Journal of Rural Studies, 16, 95-102.

18. Mabe, F. N., Nketiah, P. and Darko, D., 2014. Farmers' willingness to pay for weather forecast information in Savelugu-Nanton municipality of the Northern Region. Russian Journal of Agricultural and Socio-Economic Sciences, 36 (12), 34-44.

19. Mitchell R.C., Carson, R.T., 1989. Using surveys to value public goods: The contingent valuation method. Washington: Resources for the Future.

20. Oladele, O. I., 2008. Factors Determining Farmers, Willingness to Pay for Extension Services in Oyo State Nigeria. Agricultura Tropica et Subtropica 41 (4), 165-170.

21. Ozor, N., Garforth, C.J., Madukwe, M.C., 2013. Farmers' willingness to pay for agricultural extension service: Evidence from Nigeria. Journal of International Development, 382-392.

22. Parkinson, S., 2009. When farmers don't want ownership: Reflections on demand-driven extension in Sub-Saharan Africa. Journal of Agricultural Education and Extension, 15 (4), 417-429.

23. Rivera, W.M., Sulaiman, V.R., 2009. Extension: object of reform, engine for innovation. Outlook on Agriculture, 38 (3), 267-273.

24. Shausi, G.L., Ahmad, A.K., 2019. Factors determining crop farmers' willingness to pay for agricultural extension services in Tanzania: A case of Mpwapwa and Mvomero Districts. Journal of Agricultural Extension and Rural Development, 11 (12), 239-247.

25. Spencer, R., Mthinda, C., Masangano, C., Boyd, D., Davis, JK., 2018. Uptake and resistance: The rural poor and user-pays agricultural extension in Malawi. World Development Perspectives, 9, 48-55.

26. Temesgen D., Tola, T., 2015. Determinates of small holder farmers willingness to pay for agricultural extension services: A case study from Eastern Ethiopia. African Journal of Agricultural Research, 10(20), 2152-2158.

27. Uddin, E., Gao, Q., Mamun-Ur-Rashid, M.D., 2016. Crop Farmers' Willingness to Pay for Agricultural Extension Services in Bangladesh: Cases of Selected Villages in Two Important Agro-Ecological Zones. The Journal of Agricultural Education and Extension, 22(1), 43-60.

28. Van Crowder, L., 2000. National Agricultural Advisory Service (NAADS), FAO/World Bank Formulation Mission, Uganda. 